\title{
SHARING NEIGHBOURHOODS: BARRIERS AND DRIVERS TO SHARE SPACES AND THE ROLE OF TECHNOLOGY - THE CASE OF SUPSTAD, NORWAY
}

\author{
LARS ARNE BØ, DANIELA BAER \& KARIN HØYLAND \\ SINTEF, Norway
}

\begin{abstract}
The importance of third spaces such as libraries and cafes for community building and social interaction is undoubtable in establishing a sense of place and a feeling of belonging. Particularly in decentral urban areas, such as our case study Saupstad in Trondheim (Norway), voluntary activities play an important role in providing social meeting places. We identified technology-specific solutions that can make it easier to share spaces and thereby contribute to facilitating voluntary activities. Since most of the technological solutions on an individual level are designed for indoor space, we have chosen to focus on that, even if there are some solutions for sharing outdoor space as well. We argue that technological solutions, besides good spatial design and architecture, can foster the sharing of spaces, but several barriers limit the sharing of spaces in general and the implementation of technological solutions in particular. Based on a mapping of spaces for shared indoor spaces for voluntary activities and qualitative interviews with the users, we identified the main barriers for sharing. Additionally, interviews with commercial providers of technological solutions for space sharing and those responsible for implementing the technology were conducted to identify factors limiting and enabling the implementation of technological solutions. Our study shows that accessibility to spaces shared for voluntary activities is limited due to physical, organizational, and institutional factors. Technological applications for room booking and smart locks were identified as solutions to solve some of these challenges. We also observed that a good design and architecture of buildings and the neighbourhood in general contribute to space sharing and social participation. We conclude that a combination of technological solutions and good physical design and architecture can foster space sharing at a neighbourhood level and thereby contribute to voluntary activities taking place.
\end{abstract}

Keywords: third places, space sharing, volunteering, room sharing, smart lock technologies, case study.

\section{INTRODUCTION}

Third places are a term coined by sociologist Ray Oldenburg [1], referring to places where people spend time between home ("first" place) and work ("second" place). They are locations where people exchange ideas, have a good time and build relationships. For younger people, many functionalities of third places (such as communication etc.) are now virtual - from Facebook and chat rooms to group texts. But as Oldenburg notes, the most effective for building real community are physical places where people can easily and routinely connect with each other: churches, parks, recreation centers, hairdressers, gyms, and even fast-food restaurants.

Third spaces can be both indoors and outdoors, and there is some literature describing the importance of shared space for voluntary work and community feeling. The identity of a local community also supports social processes and the sense of belonging. Research shows, for example, that residents who feel more connected to the local community are more motivated to participate and get involved, e.g. in voluntary work [2]. An area's place identity is influenced by the two elements "sense of place" and "sense of community" [3].

In today's urban development discourse, there is a broad consensus that public spaces should be open and widely available. Public spaces constitute social meeting places where 
differences are exposed to one another, and where strangers can exchange ideas and values across different social backgrounds [4]. We adopt John Wilson's definition of volunteering [5] as "any activity in which time is given freely to benefit another person, group, or organization". In our studies we focus on institutionalised voluntary activities that are not ad-hoc but following institutional routines in the way that they occur regularly. Social sustainability in society is about the ability of the entire community, or of community at a neighborhood level, to maintain and reproduce themselves at an acceptable level of functioning.

Architect Eleni Katrini [6] says that many cities often limit themselves to residential and commercial uses, giving very little opportunities and room for communal, non-profit uses. The public and semi-public space is often not designed for sharing, which is a problem for groups and volunteer organisations.

\subsection{Case context and the suburb critic}

Saupstad, also called "the white city", is a suburb located in the south of Trondheim, Norway's third biggest city. Built in the early 1970s, Saupstad is the largest suburb in Trondheim, with a relatively stable population number around 5,000 inhabitants for the last 10 years [7]. Saupstad-Kolstad scores the lowest in Trondheim municipality on key living variables such as income level, educational level, and extent of disability benefits among residents. Furthermore, the district also has a higher unemployment rate compared to the rest of the municipality [8]. To address these challenges, a neighbourhood improvement program was initiated in the suburb [9]. Between 2012 and 2016, several measures were implemented, and new measurements are planned to be completed in 2017-2020. The neighborhood improvement program "Saupstad-Kolstad" is a collaboration between the state and Trondheim municipality. The investment should help making the district more attractive and diverse. Saupstad-Kolstad should be a district promoting quality of life and health, and there should be high quality infrastructure and public spaces in the district [9].

Saupstad has, like many newer urban areas of this period, been subject to much criticism. The suburb criticism grew stronger in the 1960s. By the end of the 1970s, a kind of common understanding seemed to be established among professionals; that the suburb would not satisfy the residents' basic need for "a good home" in "a good environment". Thus, from being an ideal in the decades just after World War II, the image of the suburb was redefined within a short time to the opposite of ideal housing, into a mistake that should not be repeated [10].

Saupstad was planned and developed according to the current principle of traffic separation and differentiation. The areas of Saupstad-Kolstad have a lot of green structure in the form of large, open areas. Furthermore, Saupstad-Kolstad is characterized as a "car-planned" district, with a relatively large area allocated for car traffic and parking. This is space-demanding, and large areas can today be considered for other uses. The road system in general forms barriers between residential areas and adjacent neighborhoods. Many people find that this gives poor accessibility between neighboring areas [10].The location and design of the buildings form a barrier to the district park and the large areas on the east side with schools, swimming pools and sports facilities [11].

"The neighbourhood improvement program" can together with The Volunteering Centre of Saupstad improve both shared space and volunteering activities in Saupstad.

The Volunteering Centre of Saupstad (VCS) was established in 2004, and forms one of the eleven "volunteering centres" in Trondheim. The centre is owned by Trondheim Red Cross and supported financially by the Municipality of Trondheim. Therefore, the range of 
activities tend to focus on the user groups that engage in volunteering at the volunteering central. The major user groups of the VCS are retirees and unemployed residents.

\subsection{Smart technology to support sharing of spaces}

Today, there are smart technologies for sharing both indoor and outdoor spaces. In this study, we have chosen to look at indoor technologies. We wanted to examine how booking technology can be used to ease access to shared spaces. In Norway and elsewhere in Europe, several companies are investing in this technology. We have identified some of the most used technologies, both in Norway and Trondheim.

The municipality of Trondheim has its own online booking system [12]. Voluntary organizations, sports clubs, cultural institutions, groups and individuals can apply to borrow or rent municipal premises when the municipality has no need to dispose of the premises themselves. Access to rooms in upper secondary schools are not included in the booking base. The secondary schools are owned by the County Council, and if you want to borrow rooms from them, you need to contact the relevant school; there is no central booking system.

Smart technology for sharing space has the potential to make life easier for people. However, this is still not much researched, and thus there is not much literature available. One article [13] has examined the current market for smart locks and identifies barriers and drivers for the future diffusion of smart lock in urban areas. A survey was conducted in London, with interviews of stakeholders in smart homes. The result shows that there are both great opportunities and barriers in the smart lock market. The researchers found that there is great uncertainty about the safety of the users, and companies must have strong client support and a security plan for the user must be prepared.

For flexible use of building spaces facilitated by digitalization and the new, a four-step principle for construction is proposed: The first step is to reduce the demand for space, the second is to intensify the usage of existing space, the third is to reconstruct and adapt existing buildings to current needs, and the fourth is to construct new buildings [13].

Another example on space sharing is Comoodle in Kirkles. A key feature of Comoodle is the desire to stimulate the sharing of underused local resources in the form of "stuff, space and skills" (Kirklees Council, 2015. They have one digital platform for sharing and it's about building new relationships and trust. It's about helping communities to thrive by thinking in new ways. Northall [14] have examined two platforms, Comoodle in Kirklees and Share Peterborough. He's founding is that there is a shift from providing services to facilitating community members and organizations to provide services themselves. That is pushing local authorities away from survival and towards a responsibilisation and marginalization narrative.

Butler, D. says in his article "Third places as community builders" [4] that if urging political, municipality, construction, and real-estate decision makers contemplate this principle, particularly in view of the new conditions that digitalization entails, that will lead to more sustainable construction and, in the long term, a sustainable built environment.

Main research questions for this article are:

1. What factors do challenge space sharing at Saupstad today?

2. What technical solutions (room booking and smart locks) are available today for space sharing in Norway, and how can they contribute to facilitate space sharing?

3. What are the main drivers and barriers to implementing technological solutions for space sharing? 


\section{METHODOLOGY}

Case studies combined with semi-structured interviews are the methods we have chosen to use in this study. We have chosen this approach to respond both to the missing literature on shared spaces and its impact on voluntary activities, and to the impact that smart technology can have on room sharing and shared space.

A case study is an empirical study that examines a challenge or phenomenon in its real context. Case studies are a suitable strategy when "how" and "where-for" issues are central [15]. They make it possible to include several methods that neutralize the disadvantages of some data collection methods. Central to this study is the different users' experience of the solution, which requires insight into the different solutions and the perspectives and experiences of the different user groups.

One criticism on the case study method is the lack of a base for generalisation from one or a few cases because data is only collected from a few examples. One common misunderstanding is to compare statistical generalisations in the natural sciences to the analytical findings of case study research. Stake [16] states that a refinement or a modification of understanding is reached through a case study ("petite generalisations"). If the goal of a research project is to generalise findings formally, other research designs than the case study would provide a stronger basis for generalisation.

Nonetheless, examples show that theories can be developed even from studying a single case [16]. These theories may be tested through investigation of other cases later. However, hypothesis testing is also possible in single-case-study research. Flyvbjerg [17], referring to Popper's falsification theory, mentions the example of the black swan. The hypothesis that all swans are white is falsified by one example of a black swan. "The case study is well suited for identifying 'black swans' because of its in-depth approach: what appears to be 'white' often turns out on closer examination to be "black"'.

In qualitative interviews, it is important to maintain the integrity of the persons interviewed both during the interview and afterwards, when the results are to be presented and inter-preted. Usually, it is a requirement that anonymous identifiable details are processed, and that sensitive information is treated with caution.

Data collection within a single case study offers the possibility for an in-depth look into the field of room sharing. Through the conducted qualitative interviews it is possible to look at trends and elucidate the themes through different point of views. We have chosen this approach to respond both to the missing literature on shared spaces and its impact on voluntary activities, and to the impact that smart technology can have on room sharing and shared space.

Semi-structured interviews were conducted both as single and focus group interviews between 2017 and 2019. We interviewed 9 persons, who are involved in space sharing in the case study area of Saupstad in Trondheim, and who either provide or use shared space for voluntary activities or play an intermediate role by facilitating sharing or voluntary activities (see Table 1). Our interviews with both private operators of technological solutions and governance responsible for implementing the public solutions on a larger scale were conducted as single interviews.

\section{SHARED SPACE IN SAUPSTAD}

We know very little about how the areas are used today, what indoor meeting places exist and how much they are used. In their quantitative survey of 2015, Rambøll [7] conducted a major resident survey on Saupstad which provides some answers to this (see Table 2).

The respondents were also asked about the places they use at Saupstad-Kolstad. The following figure illustrates the respondents' answers to this question. The majority of 
respondents respond that they frequently use Saupstad Center (78\%). In addition, common outdoor areas (51\%) and forest areas (46\%) are used frequently. Of the other places the respondents are asked about, almost half of the respondents never make use of the offers. The volunteering central and Revegården community center are the least used by the respondents. A total of $82 \%$ state that they never use the Volunteer central, while $58 \%$ never use Revegården community center Bydelshus [7].

Table 1: Interviews conducted in the case study of Trondheim and Saupstad.

\begin{tabular}{|l|c|c|c|}
\hline \multirow{2}{*}{ Interview partners } & \multicolumn{3}{|c|}{ Number and role of interview partners } \\
\cline { 2 - 4 } & Coordinator & Provider & User \\
\hline Group interview with volunteers & - & - & 3 \\
\hline Interview volunteer Saupstad & - & - & 1 \\
\hline Interview LEDI & & 1 & \\
\hline Interview Vervet & & 1 & \\
\hline Booking base Trondheim & 1 & 1 & \\
\hline Søbstad health house & & 1 & \\
\hline Huseby Secondary School & & 1 & \\
\hline
\end{tabular}

Table 2: Locations used by residents of Saupstad [7].

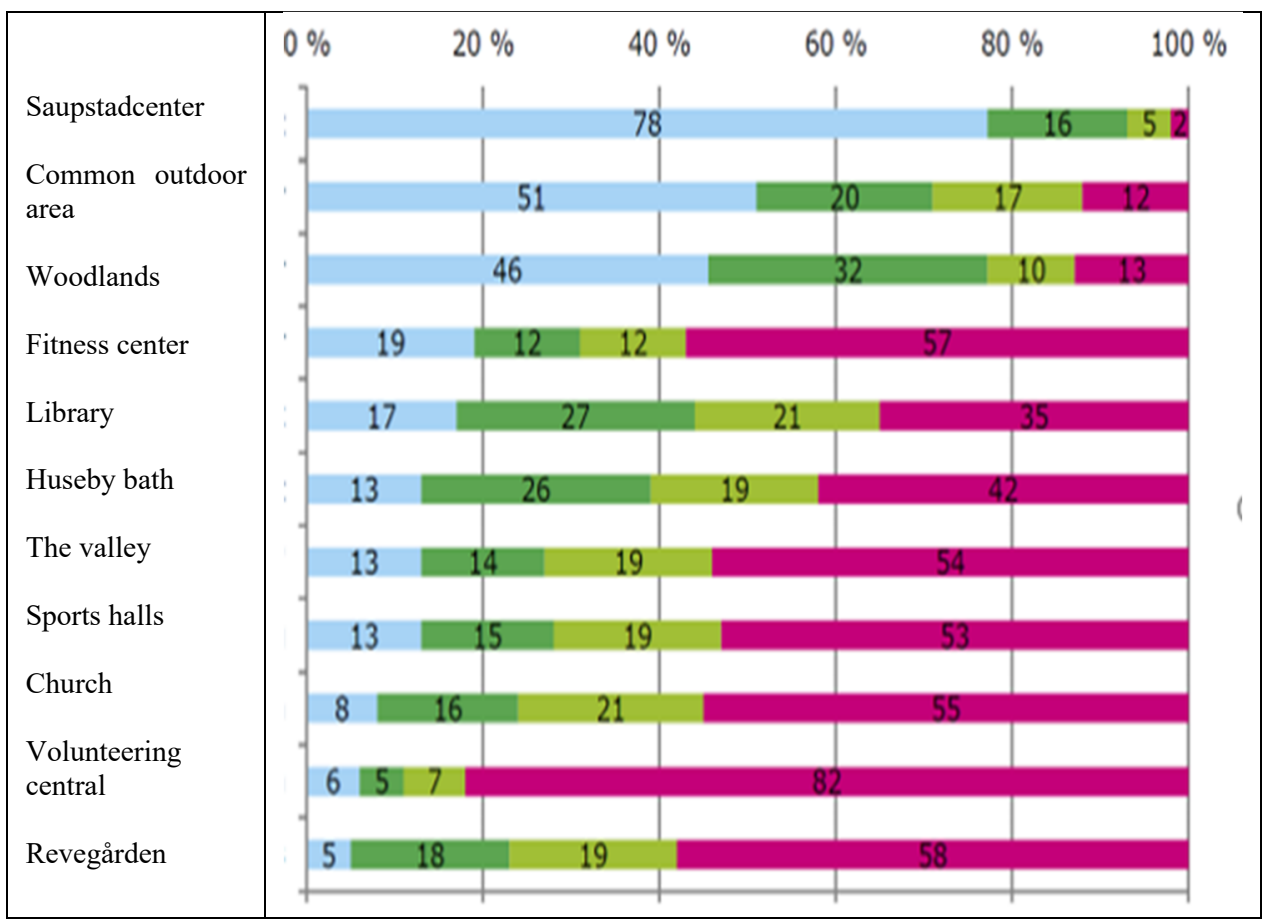

Often $\square$ Now and then $\square$ Seldom $\square$ Never. 
Table 3: Description of shared spaces in the neighbourhood of Saupstad.

\begin{tabular}{|l|l|l|l|}
\hline SHARED SPACES AND OWNERS & Facilities & Price & Providers \\
\hline 1. Kolstad church & $\begin{array}{l}3 \text { rooms of dif- } \\
\text { ferent sizes }\end{array}$ & $120-180 €$ & direct \\
\hline $\begin{array}{l}\text { 2. Meeting room E-stua in Health care } \\
\text { center, TK }\end{array}$ & 1 room & free & Via VCS \\
\hline $\begin{array}{l}\text { 3. Neighbourhood Café within Health } \\
\text { Care center (TK) }\end{array}$ & 1 room & free & Via VCS \\
\hline $\begin{array}{l}\text { 4. Library meeting room, TK } \\
\text { 5. Huseby school workshop room, TK }\end{array}$ & $\begin{array}{l}1 \text { room, 250 } \\
\text { qm }\end{array}$ & free & Via VCS \\
\hline $\begin{array}{l}\text { 6. Husebyhallen, TK } \\
\text { fport hall }\end{array}$ & free & $\begin{array}{l}\text { TK Booking- } \\
\text { base }\end{array}$ \\
\hline $\begin{array}{l}\text { 7. Heimdal high school/ Kolstad } \\
\text { Arena, County of Trøndelag }\end{array}$ & $\begin{array}{l}\text { sport hall, sev- } \\
\text { eral smaller } \\
\text { rooms }\end{array}$ & variable & Via KH \\
\hline $\begin{array}{l}\text { 8. Kolstad club house, KFC } \\
\text { kitchen }\end{array}$ & $\begin{array}{l}1 \text { room with } \\
\text { Midteggen }\end{array}$ & free & Via KFC \\
\hline $\begin{array}{l}\text { Meeting room, Housing association } \\
\text { Ming }\end{array}$ & Direct \\
\hline
\end{tabular}

There are also other rooms for sharing at Saupstad. Table 3 shows a list of rooms that can be borrowed. The municipal rooms lend their booking base via Trondheim municipality, while others like the Volunteering Center, the church and health care center book directly by contacting the respective contact person.

\section{RESULTS}

In this section, we present the findings from our interviews with the volunteers to identify how they think about room sharing in their neighborhood, and what challenges are experienced regarding space sharing. What kind of solutions there are for smart door locks and room sharing in Norway in general, and Trondheim/Saupstad, particularly. The main drivers and barriers for implementation of the solutions at Saupstad are described. This information is drawn from our interviews with both commercial providers of technological solutions and governance responsible for implementing the public solutions on a larger scale.

\subsection{Experience from volunteers in Saupstad}

Our interview partners point out that from time to time they face challenges in accessing the space for their voluntary activities. In the worst case, the building or room was not accessible, and no one was available to help. In such cases all further coordination goes to the voluntary manager. If she is not available, the voluntary event must be cancelled. "We got there and found a note on the door saying it was closed, and a message to contact the volunteer manager".

Other users report that they always need to meet the voluntary manager to get the key, making it vulnerable if the manager is ill or not available at the time. This shows that there is a great potential for technology-driven solutions that can help voluntary organizations more easily access rooms for their activities.

One problem pointed out by the interview partners was at the design level. The distance from home to the activity was too long, and many of the high-raised building blocks do not 
have elevators. For that reason, people with mobility challenges do not have the possibility to attend voluntary activities. One solution, to minimize the distance between the location of the voluntary activity and the residents, was the establishment of the "hyggetreff" (cozy meeting) activity at the location of the housing association. Due to an agreement between the VCS and the housing cooperation, the use of the facilities is free of charge.

\subsection{Smart locks and room booking in Trondheim}

On the domestic market, most Norwegians still open the door to their house or apartment with a traditional key. However, in recent years locks managed with an app on mobile phones have become more common. For a long time, Yale Doorman was almost the sole supplier of such locks in the Norwegian market, at least for private homeowners. With the rapid development of smart homes, many manufacturers are competing for this market. It is in the private housing cooperatives that smart locking systems are incorporated on a large scale in Norway. OBOS is Norway's largest housing construction company, property manager, and one of the largest residential builders in the Nordic region. By the end of 2019, OBOS had over 473,000 members. OBOS collaborates with Unlock, a company specializing in digital key solutions. In the long term, the cooperation will provide 100 housing cooperatives with digital keys [18].

Digital keys will also be able to streamline the distribution of goods and services that residents bring home. Keys can be handed out for a limited time to those in need of entry. Instead of handing out physical key copies, the door can be opened via the mobile phone. Those who are personally invited (e.g. the municipal home service, the newspaper deliverer, the food supplier or others) can get access. Digital key solutions like OBOS/Unlock are rolling out, have the potential for voluntary activities to share rooms, but this has not been tested yet. OBOS have developed the app "Neighbour help", which is a sharing app for services and goods, but does not have a space-sharing function. Akin et al. [19] has discussed whether and how digital collaborative sharing platforms can facilitate citizen engagement in urban neighborhoods by addressing various challenges experienced by local initiatives.

We have interviewed the booking base in Trondheim municipality. They report that the municipality both owns and has developed the booking base. The booking base is designed to make it possible to convey the premises that are available for use by both volunteers and private persons.

Voluntary organizations rent for free, while private individuals must pay a small fee - depending on the owner. In practice, not many people demand the extra payment. Trondheim municipality was early on with such a booking system, and today several Norwegian municipalities have developed similar systems.

To register private rooms in the booking base, has not been discussed yet. It has been a significant job to get all the local authorities into the base. Right now, they are in dialogue with the Trøndelag county council, who is interested in this system. They own the upper secondary schools, and it would have been beneficial to get both the municipal and county municipal premises together in the same database. "For those in need of room/space, it has very little significance who owns the rooms". We asked if a platform could contain all kinds of rooms; both municipal, county and private, in order to provide the best possible offer at the neighborhood level. So far, this has not been discussed; there are some restrictions both regarding the municipal model and personal protection. Today, the system is not ready for such an expansion, but this might be possible in the future.

No smart locking systems are in use in Trondheim municipality's rooms today. There are still physical keys and key cards, which are used. Some key cards have the possibility of 
programming area zones and time. At the moment, Trondheim municipality is considering testing out smart locking systems. In this phase, the considerations are the users' needs, calculations of costs, approvals for test rounds and so forth.

Trondheim municipality has looked at a system launched in Oslo this year, called "the Oslo key". "The Oslo key" [20] is app-based and allows you to open and use the municipality's available rooms. In the first stage, this applies to, among other things, recycling stations. Eventually, the key will give access to libraries, schools, and neighborhoods. Some of the services are already in the app, and more will come in 2020.

\subsection{LEDI, both digital booking and smart lock system all in one}

A system that, in theory, can include all types of rooms, is LEDI. LEDI is a service developed by the Norwegian company Skalar, which aims to create innovative solutions that people need. Their business idea is to make available public rooms that are not in use for a large part of the day. Skalar created this service to make booking of available rooms easier. LEDI is a digital citizen service (application) that makes it easy for municipalities and public buildings (and others) to rent out their premises. With LEDI, residents get clear and easily accessible rental information and a user-friendly booking process. The app lists all available rooms and various features related to the rooms. All rooms can be accessed with the use of the app; there is no need of a physical key or keycard.

Skalar reports that the major obstacle rolling out LEDI on a large scale is at the municipal level. The technology is not the source of the limitation, some of the challenges are linked to the municipality's procurement system. The procurement process for the municipalities is long and time consuming. It is a complicated system with requirements specific to a simple service such as booking. The municipality has not emphasized usability in its tenders, which means that we are competing with very little user-friendly solutions.

There may also be technological challenges in connecting LEDI to the various locking systems that exist today, and sometimes making some adjustments to the user interface will be necessary.

LEDI also reports that political support is important if it is to be established on a large scale. "It should clearly be anchored at the top, but probably more so in the fact that a clear political direction is given for rooms to be rented out and shared with the inhabitants, so that schools, etc. becomes the neighbourhood's building and not just the municipality's". Equally important is to show good examples of space sharing that could be good references for the municipality.

\subsection{Attempts to establish an experiment on Saupstad with a smart locking system}

We made an effort trying to establish a room that we could use as an experiment with a smart look system at Saupstad. Using the LEDI app, users could book time for optional activity, open and unlock with the smart lock system. The purpose was to see if the voluntary activity increased with such a booking system rather than the usual way of booking rooms and physical keys. We contacted both the Volunteer Centre and Huseby secondary school to borrow space for an experiment. We were greeted with benevolence, and both thought it was an exciting idea. What did not allow us to get such an experiment in the end, was mainly that the buildings were not designed for sharing rooms without making major changes. To be able to make changes to the lock structure on public buildings, there were a lot of bureaucracy, and our project had limited time and resources. 


\subsection{How architecture and good spatial design can foster space sharing at a neighbourhood level}

There are several important arguments for emphasizing user interests in the planning of buildings and outdoor areas. Decisions on design, planning and management of built environments affect people's everyday lives. Such changes in the built environment may allow or reduce the feeling of security, extend or restrict freedom of movement, and encourage or reduce recreational opportunities. There are concrete examples of physical surroundings that exclude people from rooms and activities [21]. The physical environment creates scripts that work differently on different people. It is important to point out that this does not imply a simplified deterministic belief in physical structure, but that physical structures together with other factors can inhibit or promote usage patterns or activities [21].

The quality of use of buildings is about how the building works in relation to the life lived there. Buildings or outdoor areas are most often built for a specific purpose, for example educational buildings, housing purposes, playgrounds or hospitals. According to the ISO standard ISO 9241, usability is defined as follows: "The extent to which a product can be used by specified users to achieve specified goals with effectiveness, efficiency, and satisfaction in a specified context of use" [22].

For both the building and the areas, it is important to discuss the building's various functions and its possibilities for innovation and development of new ways of using rooms and functions. Co-location of activities can contribute to increased cooperation between different groups [22].

Although one wishes for shared space solutions with space sharing apps and smart locking systems, we have seen at Saupstad that it can be difficult due to physical design and architecture. If the kitchen or the library is far from the entrance, access is complicated, and the rooms can be difficult to share. If we could consider shared use early in the planning phase, it will be easier to share rooms and adapt technological solutions. An example is Ydalir School in Elverum (Norway) [23], which can be split into two different zones. All the shared rooms such as the music room, library, cafeteria, and gym can be reached from the front door. This simplifies both locking solutions and prevents anyone from accessing areas they should not use. This means that the school becomes accessible to its entire neighbourhood and can be used for activities during the whole day (not only school hours), without much additional expense in managing the users.

\subsection{Private Cooperatives first on?}

As we have seen with OBOS' collaboration with Unlock, in our opinion it looks as it is in the private market that space sharing functions and smart locking systems have come the furthest in Norway. A new district plan in Tromsø has considered sharing solutions from the beginning. "Vervet" in Tromsø will become a modern district with 440 new homes and $22,400 \mathrm{~m}^{2}$ of commercial space.

At Vervet, residents can share everything from apartments for guests, cars, boats, kayaks, bicycles and rooms for all kinds of activity. What is particularly interesting, is that all sharing functions can be administered through a separate app. The app is not fully developed, but in the future, it will be possible to book all community solutions through it. The idea of Vervet is to propose several sharing solutions, but it is the residents themselves who must fill it with activity. You do not need to own more than you need, which is good in a climate perspective. 


\section{DISCUSSION AND CONCLUSION}

In our summary, we will try to answer the research questions posed in Section 1. What factors do challenge space sharing at Saupstad today? Our interview partners in Saupstad report challenges with accessing rooms for their voluntary activities. In the worst case, the building or room was not accessible, and no one was available to help. This shows that there is a great need for technological solutions that can help voluntary organizations more easily obtain space for their activities. The municipalities also have a need for these solutions, since many rooms that could have been used by voluntary organizations are empty parts of the day.

What technical solutions (room booking and smart locks) are available today for space sharing in Norway, and how can they contribute to facilitate space sharing? The technical solutions are ready to use. We have seen that there are a number of smart lock solutions, but that they are currently mainly used in private homes. Online booking systems for booking rooms are available today and used by several municipalities. Trondheim municipality uses this system today, and it works well for large groups, sport teams and larger voluntary organizations. How well it works for single persons and smaller groups, is more uncertain. There are few systems in Norway that have both room sharing features and smart locking systems integrated into the same system. LEDI and the Oslo key are examples of this. As we have seen with OBOS' collaboration with Unlock, it seems as if the private market space sharing functions and smart locking systems have come the furthest in Norway. The reason for this could be that they have a limited area and do not depend on the municipality to be able to offer the service. We conclude that a combination of technological solutions and good physical design and architecture can foster space sharing at a neighbourhood level, and thereby contribute to voluntary activities taking place.

What are the main drivers and barriers to implementing technological solutions for space sharing? The drivers for using technological applications for room booking and smart locks, are several. Those we asked, said that the desire to make everyday life easier for people is one, and finding solutions to minimize unused rooms is another. The developer of Vervet in Tromsø said that sharing solutions is environmentally friendly. For the big smart lock companies, the possibility of financial profit is probably also an incentive.

Our study shows that accessibility to spaces shared for voluntary activities with technological solutions and smart locks is limited due to physical, organizational, and institutional factors.

Organizational factors: In Trondheim there are different owners of the various public buildings. Trondheim municipality has a booking system for their rooms, the county council have another, and the Volunteering Centre of Saupstad has its own way of booking rooms. Only the municipality system is online. In Trondheim there is virtually no base for renting both public and private rooms, and none offer smart lock solutions. To achieve a common system for space sharing and smart lock systems, it must be supported by the leaders, and politicians must support the proposal.

Many neighborhoods are planned according to a structure where each building has its own purpose, which makes both sharing solutions and smart locking systems challenging. It is important to discuss the building's various functions and its possibilities for innovation and development of new, alternative solutions for using rooms and functions at an early stage of planning [21].

Does the findings section add to the knowledge we need for answering the research questions asked in this article? In many ways we think so, but it becomes especially important to document successful examples of space sharing alternatives with smart lock systems as references for the municipality and the politicians. These systems can also give a picture of whether the activity is improving and whether it is leading to more volunteer involvement 
at the neighborhood level. As a continuation of this project, we want to achieve a pilot project where we can test similar solutions for room sharing and smart locking system.

\section{ACKNOWLEDGEMENTS}

This research was conducted as part of the cooperation project "Sharing Neighbourhoods", funded by the Norwegian Research Council under the program BYFORSK (project 270737). The authors of this paper would like to thank all partners in Sharing Neighbourhoods as well as all participants involved through the presented case study.

\section{REFERENCES}

[1] Oldenburg, R., Our vanishing “third places". Planning Commissioner Journal, 25, 1997.

[2] Dury, S., Willems, J., De Witte, N., De Donder, L., Buffel, T. \& Verté, D. Municipality and neighborhood influences on volunteering in later life. Journal of Applied Gerontology, 35(6), pp. 601-626, 2016.

[3] Sampson, K. \& Goodrich, C., Making place: Identity construction and community formation through "sense of place" in Westland, New Zealand. Society \& Natural Resources, 22(10), pp. 901-915, 2009. https://doi.org/10.1080/08941920802178172.

[4] Butler, D. \& Diaz, C., "Third places" as community builders. www.brookings.edu/blog/up-front/2016/09/14/third-places-as-community-builders/. Accessed on: 16 Jun. 2019.

[5] Wilson, J., Volunteering. Annual review of sociology, 26(1), pp. 215-240, 2000.

[6] Katrini, E., Creating the everyday commons: The need to consider space in sharing initiatives, 2018.

[7] Rambøll, M.C., Kvantitativ undersøkelse for områdeløft Saupstad-Kolstad. In. Trondheim, 2015.

[8] Trondheim Municipality, Levekår 2011. Rapport om levekår i Trondheim, 2012.

[9] Trondheim Municipality, Områdeprogram for Saupstad-Kolstad 2013-2020, 2013.

[10] Hansen, T., Etterkrigstidens drabantbyer - en vellykket eller mislykket del av den norske velferdspolitikken? Tidsskrift for velferdsforskning, 2, 4, 342-250, 1999.

[11] Agraff, Parallelloppdrag med mulighetsstudie, 2013.

[12] Trondheim Municipality, Bookingbase, Lending of premises and gymnasiums. www.trondheim.kommune.no/tema/kultur-og-fritid/lokaler1/lokaler/. Accessed: 13 Jan. 2020.

[13] Bjartmyr, S. \& Hylta, P.S., Smart locks for smart customers? A study of the diffusion of smart locks in an urban area, Master's thesis, KTH Royal Institute of Technology, 2017.

[14] Northall, P.S., Platform public-sector? Local authority innovation, the sharing economy, and delivering a transition to urban economic sustainability. $\mathrm{PhD}$ thesis, University of Nottingham, 2020.

[15] Yin, R.K., Case Study Research. Design and Methods, California: Sage Publications, 2009.

[16] Stake, R.E., Case studies. Strategies of Qualitative Inquiry, eds N.K. Denzin \& Y. Lincoln, Sage Publications: Thousand Oaks, 1998.

[17] Flyvbjerg, B., 'Five misunderstandings about case-study research'. Qualitative Research Practice, eds Seale et al., Sage Publications: London, 2004.

[18] Unloc. https://unloc.app. 
342 Sustainable Development and Planning XI

[19] Akin, D., Vilarinho, T., Floch, J., Halvorsen, T. \& Baer, D., Assessing the potential of digital collaborative sharing platforms in fostering neighbourhood participation through volunteerism. International Conference on Internet Science, pp. 3-17, 2020.

[20] Oslonøkkelen. https://www.oslo.kommune.no/oslonokkelen.

[21] Høyland, K., Denizou, K., Baer, D., Evensmo, H. \& Feragen, P., Fra universelt utformede bygg til inkluderende områdeutvikling, 2018.

[22] Ryhl, K. \& Høyland, K. Inkluderende arkitektur, 2018.

[23] Ydlir School. www.ydalir.no. 